\title{
Article
}

\section{Factors that affect scrub practitioner non-technical skills: a qualitative analysis}

\author{
Mcclelland, Guy \\ Available at http://clok.uclan.ac.uk/23772/ \\ Mcclelland, Guy ORCID: 0000-0001-8053-1298 (2019) Factors that affect \\ scrub practitioner non-technical skills: a qualitative analysis. Journal of \\ Perioperative Practice, 29 (7-8). pp. 216-222. ISSN 2515-7949
}

It is advisable to refer to the publisher's version if you intend to cite from the work. http://dx.doi.org/10.1177/1750458918791112

For more information about UCLan's research in this area go to http://www.uclan.ac.uk/researchgroups/ and search for < name of research Group>.

For information about Research generally at UCLan please go to http://www.uclan.ac.uk/research/

All outputs in CLoK are protected by Intellectual Property Rights law, including Copyright law. Copyright, IPR and Moral Rights for the works on this site are retained by the individual authors and/or other copyright owners. Terms and conditions for use of this material are defined in the policies page.

\section{CLoK}

Central Lancashire online Knowledge www.clok.uclan.ac.uk

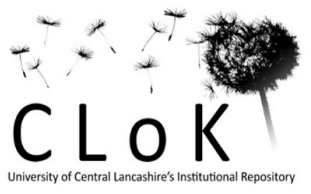




\section{Abstract}

Context - Non-technical skills are the cognitive and affective behaviours that underpin clinical practice in surgery. The purpose of this study was to explore the factors that affect how scrub practitioners use non-technical skills during surgery and their behavioural responses to those factors.

Methods - Eight scrub practitioners participated in a qualitative semi-structured interview study.

Results - Five major categories were found to affect scrub practitioner non-technical skills. These categories were democratises surgery, learns from experiences, comprehends situations, comprehends behaviours and insidious threats.

Key Findings and Implications - A scrub practitioner's ability to use non-technical skills results from the interdependent relationship of intrinsic and extrinsic motivators that affect their own behaviours, and those of their colleagues, during surgery. 


\section{$\underline{\text { Introduction }}$}

Non-technical skills (NTS) is a generic term for affective and cognitive behaviours that include leadership, teamwork, situational awareness and decision making (Flin et al 2008). Each professional grouping participating in surgery uses different NTS behaviours (Rutherford et al 2015). Scrub practitioners (SPs) are generally acknowledged to use the cognitive nontechnical skills of situational awareness and the affective skills of teamwork and communication (University of Aberdeen 2010) and to a lesser extent, decision making and leadership skills (Kang et al 2014). An external review that investigated the root causes of unintentionally retained surgical items in one NHS Trust, highlighted the contributory role of the SP in the development of serious untoward incidents (Toft 2014). Their root causes were not isolated events, but resulted from a series of complex interdependent latent conditions and errors. These included the formation of cognitive biases by surgeons and SPs that reduced situational awareness, complex interprofessional relationships that detracted from communication processes and established clinical practices that failed to mitigate errors made by fallible practitioners. This study aimed to explore the factors present within the surgical team and theatre environment that affect SP NTS and analyse how SPs respond to those factors.

\section{Methods}

Qualitative interviews were conducted to explore the factors that affect the use of NTS by SPs. Methods associated with Grounded Theory were chosen to collect and analyse interview data (Charmaz 2014). The study purposively sampled SPs recruited from an English NHS Foundation Trust. Posters promoting the study were placed in communal areas of the Trust's Operating Department and scrub practitioners were asked to contact the researcher if they wished to participate. Inclusion criterion for the study was any Operating Department Practitioner or Registered Nurse employed as a SP. Eight participants were interviewed (6 female, 2 male). The average time spent employed as a SP was 16 years (range 0.5-35 years). 
Semi-structured interviews explored the actions of the participants and their colleagues during one or two inconsequential events that had occurred during surgery. Interviews averaged 29 minutes (range 9-51 minutes) in duration. A topic guide was developed using the Scrub Practitioner List of Intraoperative Non-Technical Skills (SPLINTS) assessment framework (University of Aberdeen 2010). The interview schedule was piloted and amended following feedback. The topic guide was further amended after the fourth interview and questions revised in response to data arising from the emergent themes from preliminary interviews.

The researcher manually transcribed the recordings. Data coding commenced after the first interview to identify emergent themes and facilitate analysis of their association with themes that emerged in subsequent interviews. Analysis was undertaken by using constant comparative methods to identify similarities and differences in the data (Charmaz 2014). Validation of the emergent themes was undertaken with seven of the eight participants to prevent misrepresentation of the participants' perspectives.

\section{Ethics}

The study was approved by the NHS Trust's Research and Development Department and the School of Health Research Ethics Committee at the University of Central Lancashire. Written informed consent was obtained from all participants. Participants were able to withdraw from the research and have their data deleted for a period of up to three weeks after their interview. Data identifying an individual, location or organisation were removed during interview transcription.

\section{Findings}

Practitioners described situations during surgery that promoted or had the potential to detract from their NTS behaviours. Five major categories emerged from data analysis; democratises surgery, learns from experiences, comprehends situations, comprehends behaviours and insidious threats (see Figure 1). Each major category comprised of two or three sub- 
categories. This paper reports the findings of the democratising surgery and insidious threats categories only. Verbatim quotes from the three remaining categories are reported in Table 1.

\section{Democratising Surgery}

A key factor that facilitated the use of NTS was the ability of practitioners to communicate a concern to a colleague. Two categories emerged; speaks up and being empowered to speak up. Speaks up has two distinct sub-categories; unambiguous communication and suggestions that contain a prelude. Both forms of communication originated from participants realising that a chosen course of action was inappropriate. Most participants used unambiguous communication when a matter of urgency required an immediate response from another individual, typically when informing a surgeon that a countable item was missing.

My interpretation is that I they think it is my responsibility. Over the years, not many surgeons have asked "is the count correct?" The onus is generally on the scrub practitioner to declare that the count is correct. The surgeon doesn't take a direct interest. (Participant 6)

The perception of accountability was found to affect communication strategies. Most participants suggested unambiguous communications were necessary because item accountability was perceived as their responsibility. Communicating a missing item was delivered unambiguously because the situation was perceived as unambiguous. Some participants overcame personal characteristics that might have detracted from obtaining a response. One participant commented that their innate characteristic of quietness minimised distractions. However, the individual demonstrated their ability to modify those characteristics by altering their vocal tone whilst describing a situation when ambiguity was experienced.

Participant - I realised there was only 9 swabs. The surgeon didn't hear me at first so I asked again [participant spoke slower and slightly louder to emphasise their communication] "Is there a swab in the acetabulum? "Yes there is." And that's where the swab was. 
Interviewer - Did you find that you were able to speak up...

$P$ - Yes [very assertively - question answered before the question was completed].

I - ....to assert yourself? (Participant 5)

The response demonstrates that innate characteristics were purposefully over-ridden to obtain an immediate response from the surgeon. The surgeon's response to unambiguous communication demonstrated that speaking up allowed the practitioner to convey their concern. Consequently, the surgery was interrupted until the missing item was accounted for.

Statements or questions were guised as suggestions when a practitioner recognised that another individual's intended actions were inappropriate, and that an alternative action was desirable. One participant suggested that development of this soft skill was essential in the operating theatre.

I've learnt from having this job, you have to talk to people differently, structuring things to make it sound like it's their suggestion. It's very different. (Participant 8 )

The complexities of interprofessional working can be seen as a threat to patient safety. Participants may have difficulty communicating their comprehension of a situation to their colleagues due to established hierarchal structures. To overcome this, some participants used a prelude as a buffer to prevent the recipient of the message from perceiving that their actions were being challenged. This participant described a suggestion made to a consultant surgeon regarding the use of an alternative dressing whilst supervising a novice SP.

I said "can I just give you some advice?" trying to skirt round it as politely as I could. He was like "go on." “I don't think it's a good idea." He looked a bit surprised but he said "Okay, what do you suggest?".... [participant spoke as if the surgeon was surprised to get advice] .....and he still sounded relaxed and he said "Okay, we'll give it a try." (Participant 3) 
The practitioner recognised the consultant's status by conceding that the decision is ultimately the consultant's. However, the strategic use of the prelude "Can I just give you some advice?" resulted in the surgeon demonstrating surprise that an alternative plan had been suggested. By empowering the participant to speak up, the surgeon demonstrated that the advice of others informed his clinical decision making process. However, empowering the participant had greater symbolism. The surgeon's response demonstrated to the novice SP that speaking up is normative behaviour within perioperative culture. The act of dissemination of culturally normative behaviours may encourage the novice to also speak up to voice their concerns on future occasions.

Most of the participants described scenarios that resulted in multi-tasking whilst scrubbed. Multi-tasking during surgery was facilitated by circulating practitioners. However, the boundary formed by the surgical field also represents a professional boundary, particularly when the circulating practitioner is of a lower banding grade. Some of the participants recognised personal limitations and valued the input of their colleagues to raise safety concerns.

\section{If the circulator had seen the swab go in, and I hadn't because l'd been doing something else, I would prefer for them to say there's a swab inside. l'd say thanks for telling me that...it's a shared responsibility. (Participant 5)}

Although participants perceived that the surgeon transferred item accountability to the SP, some participants described sharing that responsibility with the circulating practitioner. This participant demonstrated that by sharing responsibility, the circulator is empowered to speak up. The circulator's challenge transcends a professional boundary that might be interpreted as questioning the participant's competence. However, by empowering an individual to speak up, the professional boundary is diminished and collective responsibility is established that may highlight safety concerns that are unrecognised by the SP. 


\section{$\underline{\text { Insidious Threats }}$}

The major category of insidious threats developed in recognition that the factors that contributed to latent threats in this study were interwoven with the existing fabric of perioperative culture. Some practitioners described clinical scenarios where colleagues violated systems that were developed to improve safety by devising work-arounds that adapted to the circumstances of surgery. The Surgical Time Out and Sign Out is a standard operating procedure briefing process that intends to transform surgical culture by promoting team working (WHO 2009). This study found that some staff demonstrate apathy towards its use by performing work-arounds that resulted in short-cuts.

The Time Out is okay, that isn't too bad. Everyone stops and listens. There are no distractions...... The Sign Out is trickier because the scrub practitioner is trying to get rid of extras, the surgeons are to the juniors "you do the notes" and he's leaving. (Participant 1)

Compliance by individual team members with the briefing process is dependent on the surgical phase. The Time Out occurs prior to surgery and appears to function as a barrier to commencing surgery. Shared situational awareness develops because the surgical team have to discuss the specifics of the case before surgery is allowed to begin. The Sign Out occurs towards the end of surgery and does not provide a barrier towards completing surgery; the barriers are the tasks that each practitioner is responsible for and greater effort is expended to complete these. The surgical team disband into their sub-teams and the resulting uncoupling reduces shared situational awareness.

The behaviours of individuals during different surgical phases suggested that some theatre teams are comprised of sub-teams that function independently and only unite for a limited period to achieve a common goal. One participant described a situation when a recovery practitioner was unavailable to recover a patient undergoing surgery. Management of the 
situation required a collaborative decision. However, the team disbanded before the surgery's completion.

She [the anaesthetist] was concentrating on the case she had... [the surgeon] was just carrying on and the assistant left to see if anything else needed doing [on the ward]. He was gone before I knew of the situation. (Participant 2)

All of the participants stated that management of similar situations defaulted to the SP. Surgical team membership is transient at the end of procedures because each individual chooses to prioritise their own responsibilities over collaboration. SPs are unable to exercise this choice because they hold membership of the surgical team for the entire duration of the surgical procedure. Consequently, the SP is conflicted between prioritising their responsibilities and managing the wider environment. Individuals are afforded differing degrees of autonomy within their clinical practice and this appears to be dependent on their role during surgery. Superficially, SPs may be perceived as having limited autonomy because they are regarded as being responsive to the needs of surgeons. By failing to collaborate, their colleagues passively delegate additional roles to the SP that conflict with tasks that must be prioritised at a particular stage of surgery.

The scenario above triangulates with the behaviours of only some clinicians during surgery. The findings demonstrated examples when participants were able to cross traditional professional boundaries and clinicians responded to concerns raised. Some participants suggested that the attitude of the recipient of the message, and not their professional status, was the barrier to their use of NTS. Two participants gave examples of episodes where "blueon-blue" conflict had the potential to emerge between practitioners from the same, or similar, professional background.

There is an innate feeling you get with certain people, you get the feeling "who do you think you are?” (participant 8)

It was more like, “you don’t have to tell me, I am qualified.” (participant 2) 
In the context of this research, the term "blue-on-blue" refers simultaneously to the traditional colour of the uniform worn by the theatre team, "theatre blues" and to the military term for "friendly fire." The presence of collegial relationships promotes effective interpersonal and interprofessional behaviours. However, in the presence of blue-on-blue conflict, a practitioner's ability to offer alternative suggestions is compromised by individuals who are unwilling to compromise their viewpoint. Acting with impunity reduces collaboration and reduces the effectiveness of individuals and the systems they function within to minimise errors.

\section{Discussion}

SPs use distinctly different communication behaviours whilst voicing concerns during surgery. The presence of a democratic system during surgery was essential to achieve this condition: speaking up and empowering others to speak up enabled this. The category of insidious threats described a series of conditions that detracted from the ability to speak up and impeded surgical democracy.

Individuals who possess hegemonic control over others are able to exercise that control to influence the behaviour of others (Crotty 1998). The surgeon's hegemonic status provides that individual with the power to dismiss the SP's concerns and continue with the progress of the surgical procedure (Gardezi et al 2009). SPs being able, or enabled, to speak up achieves the condition of democracy in surgery by redistributing power from the surgeon to other theatre practitioners and reduces established hierarchies (Finn, 2008). This study's findings suggest that SPs are aware of their ability to influence decisions made by surgeons, and use preludes in their communications to attempt to influence a surgeon's decision making. This behaviour was reciprocated by surgeons when they became aware of the potential contribution of the individual raising the concern, and empowered that individual to speak up.

The findings suggest that these egalitarian conditions may be frequently absent during surgery. Some participants suggested that some surgeons leave the operating room before 
the Surgical Sign Out or fail to acknowledge a SP communicating that all countable items are present at the end of surgery. This communication has the potential to alter the established power differentials that exist during surgery. At a fundamental level, the communication that the count is correct is the SP permitting the surgeon to complete surgery; the absence of a countable item should result in the withdrawal of permission to complete the surgery until all equipment has been accounted for. Failure to acknowledge the communication may be a manifestation of passive resistance towards the power that the SP might exercise.

At the extreme range of behaviours, participants described blue-on-blue conflict. The protagonist's behaviours introduce interpersonal tensions that were intended to actively undermine the recipient's self-efficacy. The Theory of Planned Behaviour states that an individual will choose to engage with a behaviour based on the ease or difficulty of performing that behaviour on previous occasions (Ajzen 1991). This theory explains the presence of blueon-blue conflict within the perioperative team. An individual who subjectively perceives they possess hegemonic power over another colleague may repress the behaviours of that colleague by introducing the potential for conflict. Individuals experiencing this condition during surgery may subjugate during the current surgical procedure, and on future occasions, because conforming to these subjective norms is less difficult than challenging the condition imposed up on a practitioner by another practitioner of dominant status.

\section{Limitations of This Study}

Overall, the findings have limited generalisability and transferability to SPs in other clinical settings. The study was small-scale and failed to attain theoretical data saturation. Although the clinical setting is typical of most NHS Foundation Trusts, some complex specialities had been recently re-deployed to specialist centres. SPs employed in more complex clinical specialities may have different perspectives of their experiences of using NTS (Kang et al 2015). 


\section{$\underline{\text { Conclusion }}$}

This study found that effective NTS behaviours were promoted by factors that were both intrinsic and extrinsic to the participants. Intrinsic factors manifested as each participant's personal characteristics. These characteristics resulted in behaviours that allowed the participant to function effectively on an interpersonal and interprofessional level. The participant's comprehension of the clinical situation facilitated their ability to discriminate between available options and apply the appropriate behaviour to the clinical situation. The extrinsic factors were generated by colleagues who possessed a similar comprehension of the situation and reciprocated the participants' positive behaviours with similar positive behaviours. NTS behaviours were found to have been moderated by some of the participants' colleagues being unable to discriminate between effective and ineffective behaviours. This resulted in individuals, irrespective of their hierarchal status, acting with impunity and violating systems that were intended to act as barriers against incidents occurring. SPs must be able to explicitly recognise how those factors promote or detract from their use of NTS, and be empowered by their colleagues to develop strategies that promote their use of effective NTS behaviours.

\section{References}

Ajzen I 1991 The Theory of Planned Behaviour Organisational Behaviour and Human Decision Making Processes (50) 179-211

Charmaz K 2014 Constructing Grounded Theory London, Sage

Crotty M 1998 The Foundations of Social Research: Meaning and Perspective in the Research Process London, Sage

Finn R 2008 The language of teamwork: Reproducing professional divisions in the operating theatre Human Relations 61(1) 103-130 DOI: https://doi.org/10.1177/0018726707085947

Flin R, O'Connor P, Crichton M 2008 Safety at the Sharp End: A Guide to Non-Technical Skills Farnham, Ashgate

Gardezi F, Lingard L, Espin S, Whyte S, Orser B, Ross Baker G 2009 Silence, power and communication in the operating room Journal of Advanced Nursing 65(7) 1390-1399 DOI: https://doi.org/10.1111/j.1365-2648.2009.04994.x 
Kang E, Gillespie B, Massey D 2014 What are the non-technical skills used by the scrub nurse? An integrated review Journal of Perioperative Nursing in Australia 27(4) 16-25

Kang E, Massey D, Gillespie B 2015 Factors that influence the non-technical skills performance scrub nurses: a prospective study Journal of Advanced Nursing 71(12) 2846-2857 DOI:

https://doi.org/10.1111/jan.12743

Rutherford J, Flin R, Irwin A, McFadyen A 2015 Evaluation of the prototype Anaesthetic Nontechnical Skills for Anaesthetic Practitioners (ANTS-AP) system: a behavioural rating system to assess the non-technical skills used by staff assisting the anaesthetist Anaesthesia (70)907-914 DOI: https://doi.org/10.1111/anae.13127

Toft B 2014 External Review of Never Events in Interventional Procedures Sheffield, Sheffield Teaching Hospitals NHS Trust Available from https://chfg.org/wpcontent/uploads/2015/01/External-review-redacted-version-at-the-request-of-patients.pdf [Accessed May 2018]

University of Aberdeen 2010 Scrub Practitioner List of Non-Technical Skills (SPLINTS) Aberdeen, University of Aberdeen Available from https://www.abdn.ac.uk/iprc/splints/ [Accessed May 2018]

World Health Organisation (WHO) 2009 WHO Guidelines for Safer Surgery 2009 Available from http://apps.who.int/iris/bitstream/handle/10665/44185/9789241598552_eng.pdf;jsessionid=C5FDB 48AEBF544962778018067D698EB?sequence=1 [Accessed May 2018] 


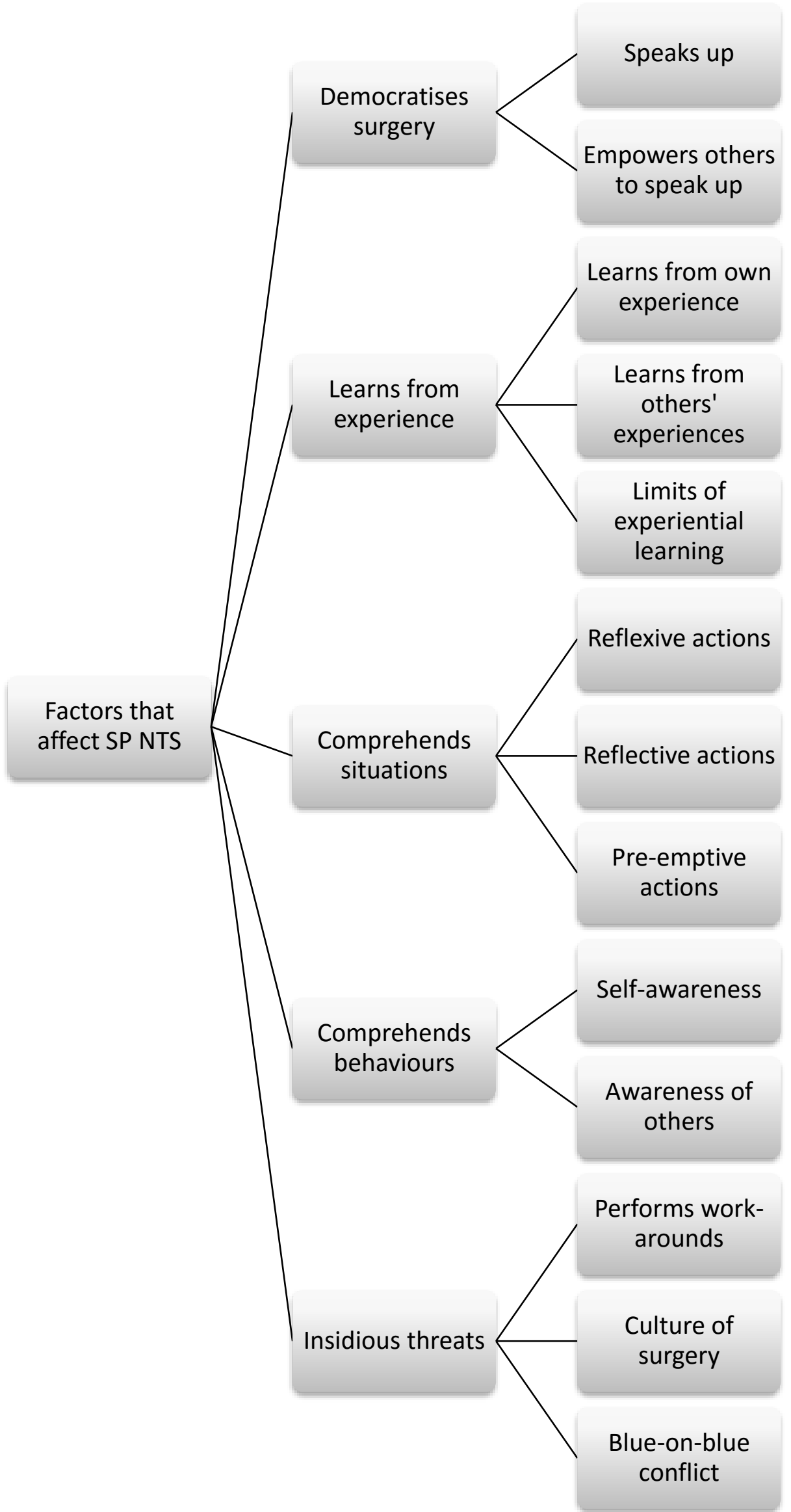




\begin{tabular}{|c|c|c|}
\hline Category & Sub-category & Illustrative quote \\
\hline $\begin{array}{l}\text { Experiential } \\
\text { learning }\end{array}$ & $\begin{array}{l}\text { Learns from } \\
\text { experience }\end{array}$ & $\begin{array}{l}\text { The competent scrub practitioner starts to identify things through experience. You start to } \\
\text { see potential incidents. People may not be aware that they are doing it but a competent } \\
\text { practitioner is making risk assessments of what's around them. (Participant } 7 \text { ). }\end{array}$ \\
\hline $\begin{array}{l}\text { Experiential } \\
\text { learning }\end{array}$ & $\begin{array}{l}\text { Learns from others' } \\
\text { experiences }\end{array}$ & $\begin{array}{l}\text { When she was de-scrubbed she said "Can you talk to me later? I am interested." It was nice } \\
\text { to share the knowledge and have somebody take it on board. (Participant } 3 \text { ) }\end{array}$ \\
\hline $\begin{array}{l}\text { Experiential } \\
\text { learning }\end{array}$ & $\begin{array}{l}\text { Limits of } \\
\text { experiential } \\
\text { learning }\end{array}$ & $\begin{array}{l}\text { I think that after two or three very similar experiences, learning wasn't as quick as I would } \\
\text { have liked it to have been, just because I thought it was a one-off. I thought we would learn } \\
\text { from it, but it carried on for a while. (Participant } 7 \text { ) }\end{array}$ \\
\hline $\begin{array}{l}\text { Comprehends } \\
\text { situations }\end{array}$ & Reflexive actions & $\begin{array}{l}\text { I can see there are swabs there but they all have blood on, none are prep swabs, so it must } \\
\text { have been at the start..... It was found in the bottom of a yellow bag and it had been thrown } \\
\text { there at the start of surgery when they prep the patient. (Participant } 4 \text { ) }\end{array}$ \\
\hline $\begin{array}{l}\text { Comprehends } \\
\text { situations }\end{array}$ & $\begin{array}{l}\text { Pre-emptive } \\
\text { actions }\end{array}$ & $\begin{array}{l}\text { As soon as l'm de-scrubbed, I knew I would have to get the difficult airway stuff ready; the } \\
\text { glidescope, the video-laryngoscope, so I put everything to the side, got rid of my sharps and } \\
\text { I said "Just leave it, we can do that any point. If we need another theatre, we have others to } \\
\text { choose from." (Participant 1) }\end{array}$ \\
\hline $\begin{array}{l}\text { Comprehends } \\
\text { situations }\end{array}$ & Reflective actions & $\begin{array}{l}\text { I asked "Do you mind me asking what you are allergic to?" and the lady said "I have a } \\
\text { sensitivity to latex" and I said "What happens when you come in to contact with latex?" "I } \\
\text { get in a rash over my whole body." I said "What happens to your airway?" "My chest gets } \\
\text { tight." I looked at the midwife and said "She's got a latex allergy hasn't she." "It's just a } \\
\text { sensitivity." ....I just said "Can you let us know, it wasn't on the notes, or you didn't tell us } \\
\text { before she came down." (Participant 3) }\end{array}$ \\
\hline $\begin{array}{l}\text { Comprehends } \\
\text { behaviours }\end{array}$ & Self-awareness & $\begin{array}{l}\text { I think you prove it by your skill and experience. When they don't know if you have a certain } \\
\text { implant and you can answer their question because they think she does know what she is on } \\
\text { about. It becomes more of a normal relationship; I think the hierarchy goes to a certain } \\
\text { degree. (Participant 4) }\end{array}$ \\
\hline $\begin{array}{l}\text { Comprehends } \\
\text { behaviours }\end{array}$ & Aware of others & $\begin{array}{l}\text { They didn't have to worry about my ability to cope with the technical side, they had faith } \\
\text { about that. The questions would follow about "how is your family?" That kind of thing. } \\
\text { (Participant } 7 \text { ) }\end{array}$ \\
\hline
\end{tabular}






